\title{
A Potential Key Role for Radionuclide Imaging in the Prediction and Prevention of Sudden Arrhythmic Cardiac Death
}

D the past few decades in reducing deaths from cardiovascular disease, the ability to identify patients at risk for sudden cardiac death (SCD) remains a challenge. SCD accounts for about 350,000 deaths annually in the United States (1). Most SCDs are from ventricular arrhythmias - ventricular tachycardia and ventricular fibrillation (VT/VF) and the means to effectively identify patients before such an event, although improving, are still limited. The question is whether a simple, noninvasive test such as radionuclide imaging with

\section{See page 225}

a suitable tracer, perhaps in combination with readily available clinical and laboratory variables, can be developed to effectively identify patients at risk for SCD.

People who experience SCD include those who have no evidence of cardiac disease and those with known cardiac disease of various types. Although the likelihood of SCD in the former group is extremely low $(0.1 \%-0.2 \%$ per year $)$, in terms of absolute numbers $(>200,000$ patients per year) it includes the majority of individuals who experience SCD (2). In this group, SCD can be the first presentation of cardiac disease in

Received Oct. 3, 2007; revision accepted Oct. 12, 2007.

For correspondence or reprints contact: Mark I. Travin, MD, Department of Nuclear Medicine, Montefiore Medical Center, 111 E. 210th St., Bronx, NY 10467-2490.

E-mail: mtravin@attglobal.net

COPYRIGHT (C) 2008 by the Society of Nuclear Medicine, Inc.

DOI: 10.2967/jnumed.107.046821 an otherwise "healthy" person, certainly a catastrophe for someone in the prime of life, and for the family. Yet, despite the high numbers at risk, the extremely low likelihood of SCD in any individual person makes it difficult to screen for. In these patients, coronary artery disease is usually silently present, with acute ischemia being the arrhythmic initiator. An approach along the lines of the SHAPE (Screening for Heart Attack Prevention and Eradication) initiative, using a combination of risk factor screening and management, and judicious use of noninvasive testing, may be best and most cost-effective (3). A role for imaging to specifically detect vulnerability to VT/VF arrhythmias in these patients remains to be determined and is beyond the scope of this discussion.

Among patients with known disease, some have a primary arrhythmic abnormality, such as prolonged QT syndrome or Brugada syndrome. These abnormalities are less common and often respond to therapies specific for the condition. Radionuclide imaging has shown potential utility in these syndromes (4).

By far, the most attention has been paid to prevention of VT/VF SCD in patients with known ischemic coronary artery disease, often accompanied by left ventricular dysfunction, and those with nonischemic cardiomyopathy. Therapies aimed at the underlying disease reduce overall mortality, including the risk of SCD. Unfortunately, pharmacologic therapy aimed specifically at preventing VT/VF SCD has been disappointing and in some instances harmful $(5,6)$. It is currently accepted that patients who meet defined criteria are best treated with an implantable cardioverter defibrillator (ICD), shown to significantly reduce SCD and enhance overall patient survival (1,7-9). In MADIT II (Multicenter Automatic Defibrillator Implantation Trial), compared with conventional medical therapy an ICD resulted in a $31 \%$ reduction in the risk of death for patients with prior myocardial infarction and a left ventricular ejection fraction (LVEF) of $30 \%$ or less (8). In SCD-HeFT (Sudden Cardiac Death in Heart Failure Trial), an ICD led to a $23 \%$ reduction in death by $5 \mathrm{y}$ in patients with New York Heart Association class II-III congestive heart failure and an LVEF of $35 \%$ or less (9).

However, ICD implantation has numerous related problems. First, despite a striking reduction in relative mortality, the absolute reduction in mortality is less impressive, about $6 \%-7 \%$ in the aforementioned trials. Given that implantation of an ICD costs about $\$ 28,000$ (10), a better way is needed than having to treat 100 patients to save fewer than 7. ICD implantation also has potential adverse consequences, including operative complications, device malfunction, pain, psychiatric problems associated with shocks, lifestyle restrictions, and the potential of interfering with a peaceful death when VT/VF is the endsequela of death rather than the primary cause. This last consequence emphasizes the need to identify a patient's risk of VT/VF as the primary cause of death. Much SCD is not responsive to the ICD, including SCD from electromechanical dissociation and from noncardiac causes $(11,12)$.

To more effectively select patients for ICD therapy and thereby reduce VT/ VF SCD, one needs a better understanding and application of the underlying 
mechanisms of life-threatening arrhythmias. Although these mechanisms are complex and related to a variety of structural and physiologic abnormalities, there is much evidence that disorders of the cardiac autonomic nervous system are often key factors $(13,14)$. An association between cardiac autonomic innervation abnormalities and cardiac death has been shown in various ways, such as by measuring heart rate variability (15). Among survivors of myocardial infarction or resuscitated cardiac arrest, and in patients with nonischemic cardiomyopathies, abnormalities in heart rate variability have been shown to be related both to all causes of mortality and to arrhythmic mortality (16-18).

Given its unique abilities to assess physiologic and molecular processes, radionuclide imaging is well suited to determining the state of cardiac autonomic innervation. There is consistent evidence that imaging cardiac sympathetic innervation using norepinephrine radionuclide analogs, such as ${ }^{123}$ I-metaiodobenzylguanidine (MIBG) or ${ }^{11} \mathrm{C}$-hydroxyephedrine, predicts mortality in patients with a variety of cardiac conditions $(19,20)$. Several studies have shown that imaging with ${ }^{123} \mathrm{I}-\mathrm{MIBG}$ risk-stratifies patients as well as or better than other strong prognostic variables, such as LVEF or serum brain natriuretic peptide $(21,22)$.

A particular strength of ${ }^{123}$ I-MIBG imaging may be its ability to specifically predict the likelihood of VT/VF arrhythmias (23-25), indicating the potential to identify patients who would benefit from an ICD. One recent small study with 17 patients saw that various ${ }^{123}$ I-MIBG planar and SPECT image parameters, as well as combined ${ }^{123} \mathrm{I}$ MIBG and heart rate variability variables, correlated with the likelihood of a defibrillator discharge in patients who already had an ICD (26).

The study by Nagahara et al. in this issue of the Journal of Nuclear Medicine expands our knowledge of the potential use of cardiac autonomic imaging with

${ }^{123}$ I-MIBG to select patients at risk of VT/VF SCD who would benefit from an ICD (27). In 54 patients who had received an ICD based on published indications, the occurrence of an event-SCD or an ICD discharge triggered by a potentially lethal arrhythmia as determined by querying of the builtin memory system of the ICD-strongly correlated with the late ${ }^{123}$ I-MIBG heartto-mediastinum ratio (HMR) (hazard ratio, $0.141 ; P=0.008$ ), independent of numerous other variables including LVEF that did not achieve statistical significance. At the same time, combining HMR with LVEF or with brain natriuretic peptide gave additional predictive power. From receiver operating characteristic analysis, event predictive thresholds for late HMR (1.95), LVEF (50\%), and brain natriuretic peptide (187 $\mathrm{pg} / \mathrm{mL}$ ) were derived. Combining the HMR and LVEF thresholds produced a positive predictive value of $58 \%$ and a negative predictive value of $77 \%$, and combining the HMR and brain natriuretic peptide thresholds produced values of $82 \%$ and $73 \%$, respectively. Consider that although these numbers are well below $100 \%$, they are better than the currently accepted criteria of an EF of less than $35 \%$, which had a positive predictive value of only $19 \%$ in SCDHeFT (9). In addition, although in the post-myocardial infarction population LVEF criteria identify fewer than half of patients who experience $\operatorname{SCD}(28)$, in the study of Nagahara et al. the combination of LVEF and HMR had a sensitivity of $67 \%$. Given the dire consequences of not putting an ICD in someone who subsequently has a VT/VF arrest, it is crucial that the sensitivity and negative predictive value of any criteria used to decide implantation be close to $100 \%$, with a reasonably high specificity and positive predictive value.

For sure, the relatively simple, noninvasive ICD selection criteria proposed in the study of Nagahara et al. promises improvement over what is currently used. At the same time, as the statistical power of these data is well below that of the multicenter ICD studies containing thousands of patients, further validation is mandatory. In addition, before ${ }^{123}$ I-MIBG or any other radionuclide imaging technique can be accepted for clinical use as an ICD selection tool, the results of this study must be supported by a large, prospective study. An industrysponsored, multicenter international study that is currently under way, examining the prognostic value of ${ }^{123} \mathrm{I}$ MIBG in patients with New York Heart Association class II-III and an LVEF of $35 \%$ or less, many of whom have ICDs that can be interrogated, promises to provide comprehensive data. Finally, it remains to be seen how radionuclide autonomic imaging compares with assessment of electrocardiographic microvolt T-wave alternans, a technique recently reported to show much promise for selection of patients who would benefit from an $\operatorname{ICD}(29,30)$.

In the current era, imaging is under much scrutiny (31). In particular, to thrive and prosper, cardiac radionuclide imaging must be shown to have a unique and beneficial effect on patient outcome, and clear appropriateness criteria must continue to be developed and applied. Because radionuclides assess molecular processes, and because these processes are the underlying basis of much disease, nuclear imaging offers great promise in this regard. A radionuclide imaging technique that can easily and reliably help prevent SCD would be most welcome.

\section{Mark I. Travin \\ Montefiore Medical Center and Albert Einstein College of Medicine \\ Bronx, New York}

\section{REFERENCES}

1. Zipes DP, Camm AJ, Borggrefe M, et al. ACC/ AHA/ESC 2006 guidelines for management of patients with ventricular arrhythmias and the prevention of sudden cardiac death-executive summary: a report of the American College of Cardiology/ American Heart Association Task Force and the European Society of Cardiology Committee for Practice Guidelines (Writing Committee to Develop Guidelines for Management of Patients with Ventricular Arrhythmias and the Prevention of Sudden Cardiac Death. J Am Coll Cardiol. 2006; 48:1064-1108.

2. Huikuri HV, Castellanos A, Myerburg RJ. Sudden death due to cardiac arrhythmias. $N$ Engl J Med. 2001;345:1473-1482.

3. Naghavi M, Falk E, Hecht HS, et al., for the SHAPE Task Force. From vulnerable plaque to vulnerable patient: part III-executive summary for the Screening for Heart Attack Prevention and Education (SHAPE) Task Force report. Am J Cardiol. 2006;98(suppl):2H-15H. 
4. Wichter T, Matheja P, Eckardt L, et al. Cardiac autonomic dysfunction in Brugada syndrome. Circulation. 2002;105:702-706.

5. Cairns JA, Connolly SJ, Roberts R, et al. Randomised trial of outcome after myocardial infarction in patients with frequent or repetitive ventricular premature depolarization: CAMIAT. Canadian Amiodarone Myocardial Infarction Arrhythmia Trial Investigators. Lancet. 1997;349:675-682.

6. Echt DS, Liebson PR, Mitchell LB, et al., and the CAST investigators. Mortality and morbidity in patients receiving encainide, flecainide, or placebo. The Cardiac Arrhythmia Suppression Trial. N Engl J Med. 1991;324:781-788.

7. Buxton AE, Lee KL, Fisher JD, Josephson ME, Prystowsky EN, Hafley G. A randomized study of the prevention of sudden death in patients with coronary artery disease. Multicenter Unsustained Tachycardia Trial Investigators. N Engl J Med. 1999; 341:1882-1990.

8. Moss AJ, Zareba W, Hall WJ, et al., for the Multicenter Automatic Defibrillator Implantation Trial II Investigators. Prophylactic implantation of a defibrillator in patients with myocardial infarction and reduced ejection fraction. $N$ Engl $J$ Med. 2002;346:877-883.

9. Bardy GH, Lee KL, Mark DB, et al. Amiodarone or an implantable defibrillator for congestive heart failure. N Engl J Med. 2005;352:225-237.

10. Sanders GD, Hlatky MA, Owens DK. Costeffectiveness of implantable cardioverter-defibrillators. N Engl J Med. 2005;353:1471-1480.

11. Anderson KP. Risk assessment for defibrillator therapy. J Am Coll Cardiol. 2007;50:1158-1160.

12. Anderson KP. Sudden cardiac death unresponsive to implantable defibrillator therapy: an urgent target for clinicians, industry, and government. J Interv Card Electrophysiol. 2005;14:71-78.

13. Zipes DP, Wellens HJJ. Sudden cardiac death. Circulation. 1998;98:2334-2351.
14. Barron HV, Lesh MD. Autonomic nervous system and sudden cardiac death. J Am Coll Cardiol. 1996; 27:1053-1060.

15. Barron HV, Viskin S. Autonomic markers and prediction of cardiac death after myocardial infarction. Lancet. 1998;351:461-462.

16. Kleiger RE, Miller JP, Bigger JT, Moss AJ, and the Multicenter Post-Infarction Research Group. Decreased heart rate variability and its association with increased mortality after acute myocardial infarction. Am J Cardiol. 1987;59:256-262.

17. Bigger JT, Fleiss JL, Rolnitzky LM, Steinman RC. The ability of several short-term measures of RR variability to predict mortality after myocardial infarction. Circulation. 1993;88:927-934.

18. Ponikowski P, Anker SD, Chua TP, et al. Depressed heart rate variability as an independent predictor of death in chronic congestive heart failure secondary to ischemic or idiopathic dilated cardiomyopathy. Am J Cardiol. 1997;79:1645-1650.

19. Carrió I. Cardiac neurotransmission imaging. J Nucl Med. 2001;42:1062-1076.

20. Lautamäki R, Tipre D, Bengel FM. Cardiac sympathetic neuronal imaging using PET. Eur J Nucl Med Mol Imaging. 2007;34(suppl):S74-S85.

21. Merlet P, Valette H, Dubois-Randé JL, et al. Prognostic value of cardiac MIBG imaging in patients with heart failure. J Nucl Med. 1992;33: 471-477.

22. Matsui T, Tsutamoto T, Maeda K, Kusukawa J, Kinoshita M. Prognostic value of repeated ${ }^{123} \mathrm{I}-$ metaiodobenzylguanidine imaging in patients with dilated cardiomyopathy with congestive heart failure before and after optimized treatments: comparison with neurohumoral factors. Circ J. 2002;66: 537-543.

23. Stanton MS, Tuli MM, Radtke NL, et al. Regional sympathetic denervation after $\mathrm{MI}$ in humans detected noninvasively using I-123-MIBG. $J$ Am Coll Cardiol. 1989;14:1519-1526.
24. McGhie AI, Corbett JR, Akers MS, et al. Regional cardiac adrenergic function using I-123 MIBG SPECT imaging after acute myocardial infarction. Am J Cardiol. 1991;67:236-242.

25. Hayashi M, Kobayashi Y, Iwasaki Y, et al. Longterm variability in induced ventricular tachyarrhythmias: incidence, background, and clinical significance in relation to the spontaneous occurrence of arrhythmias [abstract]. Circulation. 2000; 102:II-713.

26. Arora R, Ferrick KJ, Nakata T, et al. I-123 MIBG imaging and heart rate variability analysis to predict the need for an implantable cardioverter defibrillator. J Nucl Cardiol. 2003;10:121-131.

27. Nagahara D, Nakata $T$, Hashimoto A, et al. Predicting the need for an implantable cardioverter defibrillator using cardiac metaiodobenzylguanidine activity together with plasma natriuretic peptide concentration or left ventricular function. $\mathrm{J} \mathrm{Nucl}$ Med. 2008;49:225-233.

28. Buxton AE, Lee KL, Hafley GE, et al., for the MUSTT Investigators. Limitations of ejection fraction for prediction of sudden death risk in patients with coronary artery disease. J Am Coll Cardiol. 2007;50:1150-1157.

29. Chan PS, Stein K, Chow T, Fendrick M, Bigger JT, Vijan S. Cost-effectiveness of a microvolt Twave alternans screening strategy for implantable cardioverter-defibrillator placement in the MADITII-eligible population. J Am Coll Cardiol. 2006;48: 112-121.

30. Chow T, Kereiakes DJ, Bartone C, et al. Microvolt $\mathrm{T}$-wave alternans identified patients with ischemic cardiomyopathy who benefit from implantable cardioverter-defibrillator therapy. J Am Coll Cardiol. 2007;49:50-58.

31. Gibbons RJ. Leading the elephant out of the corner: the future of health care-presidential address at the American Heart Association 2006 scientific sessions. Circulation. 2007;115:2221-2230. 